\title{
UNA INVESTIGACIÓN SOBRE EL TINGLADO: EL DEPORTE COMO ASUNTO ACADÉMICO Y EL BOXEO COMO TEMA ANTROPOLÓGICO ${ }^{1}$ AN INVESTIGATION ON THE RING: THE SPORT LIKE ACADEMIC MATTER AND THE BOXING LIKE ANTHROPOLOGIC TOPIC
}

David Leonardo Quitián Roldán²

\section{Resumen}

\begin{abstract}
Explorar las connotaciones socioculturales, de una práctica corporal intensa como el boxeo, resultó una aventura académica de dimensiones insospechadas. Quizá suene exagerado afirmarlo así, pero no se puede negar que eso es, en el fondo, lo que buscan todas las indagaciones antropológicas: desentrañar el ADN cultural que fundamenta folclores particulares y universales. Hallar en la aldea el genoma de la civilización. El presente artículo reseña el paso a paso de un trabajo de grado (tesis) propuesto y desarrollado en la maestría de antropología de la Universidad Nacional de Colombia. Cómo un tema sin tradición en ciencias sociales y cómo un deporte tan oscuro y poco estudiado como el pugilato fueron abordados debe provocar, al menos, curiosidad académica. De contera, examinar la metodología (una etnografía), el basamento teórico (plagado de citas literarias, musicales y cinematográficas) y los hallazgos, puede ilustrar no sólo de las dificultades y oportunidades de un trabajo de este tipo, sino animar al sondeo de otros caminos en la escritura de textos científicos. Finalmente, ubicar el deporte como hecho social total y, dentro de él, al boxeo, contribuye a superar el rezago intelectual que suponía que los deportes eran temas baladíes que nada tenían que decirnos de lo que somos. Síntesis de lo que significa el boxeo para los colombianos en dónde el lenguaje también se sube al ring.
\end{abstract}

Palabras clave: deporte y academia, antropología y boxeo, etnografía, literatura, periodismo e identidad local.

Abstract

Explore the cultural connotations of intense bodily practice as boxing, was an academic adventure of unexpected dimensions. Say so may sound exaggerated, but there is no denying that this is, basically, they look all anthropological inquiries: unraveling the cultural DNA that underlies particular and universal folklore. Found in the village the genome of civilization. This article outlines the step by step from a thesis (a thesis) proposed and developed in the mastery of anthropology at the Universidad Nacional de Colombia. How a subject without tradition in social sciences and how a sport so obscure and little studied as the boxing were addressed should raise at least academic curiosity. From tip to examine the methodology (ethnography), the theoretical basis (full of literary quotations, music and film) and the findings may illustrate not only the difficulties and opportunities of such work, but encourage other poll roads in the writing of scientific texts. Finally, place the sport as a total social fact and, within it, to boxing, helping to overcome the intellectual backwardness that sports were supposed to trivial matters that had nothing to tell us what we are. Summaries of what it means for the Colombian boxing where language gets in the ring also.

Key words: sport and academy, anthropology and boxing, ethnography, literature, journalism and local identity.

Fecha de recepción: 28 de Septiembre de 2010

Fecha de aprobación: 29 de Octubre de 2010

\footnotetext{
${ }^{1}$ Artículo surgido de la tesis La sobrecogedora experiencia de ser boxeador en Bogotá: un ejercicio etnográfico en el mundo de las narices chatas (2009) que fue distinguida como meritoria, por la Maestría en Antropología, de la Facultad de Ciencias Humanas de la Universidad Nacional de Colombia.

${ }^{2}$ Sociólogo y Magister en Antropología de la Universidad Nacional de Colombia. Profesor Universidad Pedagógica Nacional, Universidad Incca de Colombia y Universidad de los Llanos. Presidente de la Asociación Colombiana de Investigación y Estudios Sociales del Deporte - ASCIENDE. Miembro del comité científico de la Asociación Latinoamericana de Estudios Socioculturales del Deporte - ALESDE. quitiman@yahoo.es
}

Universidad Pedagógica Nacional 


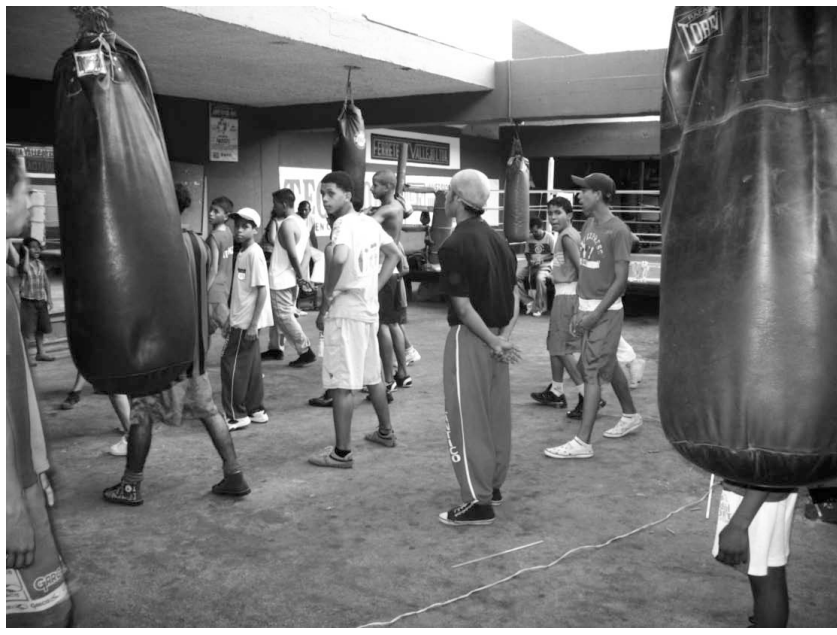

Figura 1. Entrenamiento en Gimnasio Elías Chegwin de Barranquilla

Primer round: la lucha por la aceptación del proyecto

Es conocido por todos que, para que un trabajo de grado sea aceptado en el seno de una maestría, se debe justificar su pertinencia, debe estar avalado y acompañado por un director de tesis (generalmente un profesor de la universidad ofertante del posgrado) y debe dar cuenta de la información como los antecedentes (una especie de estado del arte del tema propuesto, en donde se detalle investigaciones y autores existentes sobre el particular); además de explicitar el marco teórico (teorías, posturas, enfoques que sirvan de fundamento o referente académico), metodología (herramientas y modos de uso de ellas, tanto en el acopio y recolección de datos como en el análisis y comprensión de los mismos), cronograma (fases y tiempos de la investigación) y bibliografía (textos generales y específicos no sólo del tema en cuestión, sino también de la metodología y del cómo y para qué investigar). Todos esos requisitos obran para cualquier proyecto de grado en todas las academias del mundo; no obstante su observancia si difiere, como dijera Max Webber (1997) "con intereses con arreglo a fines".

En otras palabras, los proyectos deben guardar alguna relación con las líneas de investigación preexistentes en el programa de posgrado seleccionado (tradición compresible, pero no siempre democráti$\mathrm{ca}$, sobre la que se sostienen fortalezas investigativas y prestigios académicos) y deben tenerse en cuenta otros factores, en apariencia menores, como la disponibilidad de algún profesor investigador para asumir la dirección de la tesis y la aprobación del tema por parte del consejo académico de la respectiva maestría. Aceptación que, a su vez, entraña un carácter subjetivo y que se toma valorando las capacidades argumentativas del investigador proponente; así como el cumplimiento de aspectos formales (fechas límites de entrega, aval del director, diligenciamiento acorde del formato exigido y respeto de las normas de presentación de trabajos) y de fondo (solvencia teórica, sindéresis en la presentación de motivos, metodología y enunciación de objetivos) en el documento presentado y en la exposición que se haga del mismo.

Elementos que encarnan dificultades (también oportunidades, es justo decirlo) y que demandan ciertas habilidades de parte del investigador. En consecuencia, si el tema y las preguntas del investigador no coinciden con los nichos de interés de las líneas y los grupos de investigación del programa, la probabilidad de ser aceptado se reduce; de igual manera, si la perspectiva de acercamiento del problema, la metodología esbozada, los autores escogidos y la propia manera de escribir no son del gusto ni sintoniza con la sensibilidad académica del comité (o de algunos de sus miembros) que aprueba o deniega los proyectos, las posibilidades de ver la luz verde, también se contraen.

Por todo ello, arriesgarse a proponer temas inéditos, tanto en su esencia, como en su aproximación, constituye un procedimiento inseguro que puede terminar en sucesivas negativas o en trabas para desarrollar el trabajo en un ambiente ideal. Para el caso que aquí se expone, la presentación del proyecto de grado La sobrecogedora experiencia de ser boxeador en Bogotá: un ejercicio en el mundo de las narices chatas ${ }^{3}$, en el seno de la Maestría en Antropología de la Universidad Nacional de Colombia, se tradujo en la dificultad para relacionarla con alguna de las líneas investigativas vigentes y para seducir, o al menos comprometer, a algún profesor en su dirección. Hubiese resultado más sencillo acometer un tema del canon disciplinar (antropológico) o en caso de no querer abandonar el campo trabajar

\footnotetext{
${ }^{3}$ Primera tesis de nivel de maestría, en la Universidad Nacional de Colombia, que tuvo como tema al deporte. Guillermo Montoya (Universidad de los Andes, 2009) y Jorge Ruiz (Universidad Javeriana, 2210) son otros autores con tesis de maestría con temas sobre deporte desde la perspectiva de las ciencias sociales.
} 
un problema relacionado con el fútbol (el más estudiado de los deportes) ó con la violencia asociada al balompié, específicamente el de las barras que cuentan con varios estudios en Colombia ${ }^{4}$.

Ahorrando los detalles que signaron el curso de la concepción, presentación y aprobación del proyecto, diremos que el director que lo asumió fue el doctor Roberto Pineda Camacho (2000), un reconocido antropólogo en el tema indigenista y que ha logrado renombre internacional con sus investigaciones sobre la violenta explotación del caucho de la Casa Arana en el Putumayo y Amazonas.

\section{Segundo round: primeros golpes en la arena académica}

Confeccionar la estrategia de la investigación requirió más de una consulta con los profesores de metodología de la maestría y varias reuniones de trabajo con el director Roberto Pineda. Elaborar una tabla de contenido resultó el experimento más eficaz: delinear en capítulos la pesquisa sirvió para precisar temas y para priorizarlos. A raíz de esos devaneos, se depuraron las preguntas, se definió el universo de los sujetos de la observación (incluida su geografía, porque la investigación arrancó en Bogotá y termino en las dos costas de Colombia), se ratificó que la metodología sería una inmersión etnografía y se redactaron por última vez los objetivos. Así mismo, se dio libertad para explorar maneras de narrar. La forma escogida fue la primera persona del singular. La siguiente es la transcripción del esqueleto formal que se extrajo de esos ejercicios de planeación:

\section{Resumen}

A lo largo de 7 meses, se hará una observación directa y profunda del ambiente cotidiano en el que se desenvuelven los pugilistas de "alto rendimiento" inscritos en la Liga de Boxeo de Bogotá. Dicha mirada constituye un ejercicio antropológico en la medida en que se fundamenta en el trabajo de campo -la etnografía- que busca la construcción progresiva de un "metarrelato" (una versión literaria, en todo caso) que de cuenta del entorno particular en el que

${ }^{4}$ Las investigaciones de Harold Pardey La ciudad de los fanáticos, 2000, de Germán Gómez Eslava La violencia en el fútbol vista a través de las barras bravas, 2001 y de María Teresa Salcedo con Rivera Omar Emoción, control e identidad. Las barras bravas de fútbol en Bogotá, 2008 son los tres estudios más conocidos. coexisten los deportistas en cuestión, incluidos sus intereses, motivaciones, prácticas, imaginarios y expresiones discursivas.

Objetivo general

- Construir un producto antropológico (literario) que mediante un trabajo de campo (una etnografía) intente satisfacer tres preguntas: ¿qué significa ser boxeador?, ¿cómo se fabrica un pugilista en Bogotá?, y ¿cuál es la relación entre deportista y territorio y deportista y ciudad?

\section{Objetivos específicos}

- Determinar si las condiciones históricas que la literatura, la academia, la prensa y la imaginería pública han determinado como elementos constitutivos del oficio pugilístico son las que caracterizan al boxeo en Bogotá.

- Investigar qué papel juegan, en el imaginario de los boxeadores distritales, figuras icónicas del pugilato nacional como "Pambelé" y el "Happy Lora" e internacionales como Muhammad Ali, Carlos Monzón y Mike Tyson.

- Establecer si en la comunidad observada existe algún tipo de relación entre los lugares de origen, las procedencias, las afinidades étnicas y regionales y el deporte practicado.

- Elaborar una exposición cronológica que relacione las circunstancias y los hechos más importantes de la llegada del boxeo a Colombia, sea en su propia expresión deportiva o en expresiones afines como la lucha libre y/o la esgrima.

- Proponer con este trabajo y con el producto emanado de él, una línea de investigación en la Facultad de Ciencias Humanas, en específico, y en la Universidad Nacional en general, sobre temáticas como el ocio, el juego, la recreación, la educación física y el deporte.

\section{Información del proyecto}

\section{¿Cuál es la comunidad de estudio?}

- Los 12 pugilistas de alto rendimiento de la Liga de Boxeo de Bogotá.

- Todos son hombres y sus edades oscilan entre los 16 y los 25 años.

- Ninguno es bachiller y 9 son afrodescendientes.

\section{¿Dónde están ubicados?}

- Todos viven en Bogotá, pero sólo tres han nacido en la ciudad.

- Habitan en barrios del centro y el sur de la capital (estratos socioeconómicos 2 y 3 ). 
- Su lugar de entrenamiento es el gimnasio ubicado en el complejo deportivo El Salitre.

\section{¿Qué periodo se va a estudiar?}

- El rango de tiempo a escrutar va desde finales de marzo a finales de septiembre de 2007 (7 meses).

- Un ciclo de preparación completa, es decir, el tiempo de entrenamiento intermedio que va desde la última pelea oficial, hasta la intervención deportiva en la siguiente velada boxística (un promedio de seis meses).

\section{Síntesis metodológica ¿cómo se va a hacer?}

\section{Genéricamente}

- Invocando la Magia del etnógrafo de Malinowski (1975).

- Particularmente

- Conviviendo una semana (de lunes a lunes) con dos de ellos: con el más joven y con el de más edad (una de las semanas de inmersión será al comienzo del ciclo preparatorio y la otra al final del mismo) en la que se llevará un registro de notas (diario de campo).

- Escrutando con detalle la producción periodística, surgida en el periodo de observación (el año), que tenga relación directa con los sujetos de estudio (por ejemplo, dos de los boxeadores seleccionados pelearán por un título nacional y por una corona centroamericana).

- Recreando en diez viñetas, diez momentos distintos (y aleatorios) en la vida de los pugilistas; seleccionando una de las viñetas como producto a profundizar en la forma de un estudio de caso (una observación profunda que a futuro pueda desarrollarse como una historia de vida o como una biografía histórica).

- Entrevistando a los informantes privilegiados (entrevistas formales e informales, superficiales y en profundidad sean estructuradas y/o semiestructuradas) que versen sobre:

- Sus lugares de origen y entornos socioculturales de infancia.

- Sus sueños de infancia, sus estudios, sus creencias religiosas y políticas.

- Las motivaciones para ser deportistas y boxeadores.

- Los intereses para desplazarse a Bogotá (aplica para siete informantes).

- Sus prácticas cotidianas fuera del tinglado/ Sus rutinas de entrenamiento.
- Qué sienten en un día de pelea y cómo viven un combate.

- La opinión que tienen de su oficio, de sus colegas, de los espectadores que los ven y los siguen; de los entrenadores, los periodistas y los dirigentes deportivos.

- Sus expectativas futuras de vida.

En el tercer capítulo de la tesis se ilustra de mejor manera la metodología:

Pues bien, mi idea, que nunca supe explicar bien a los entrenadores y boxeadores, no era hacer un reportaje de Pambelé, ni uno tributario del clásico periodismo (o sí, pero en el sentido del reportazgo etnográfico que hiciera Óscar Lewis en el Défé), sino un conjunto de observaciones, vivencias y entrevistas que me permitieran responder las mismas preguntas que Pierre Loïc Wacquant se hiciera en un gym del gueto negro de Chicago: ¿qué significa ser boxeador? y ¿cómo se fabrica un boxeador?... que fueron mutando por otras del tenor ¿qué significa ser un boxeador negro? y ¿cómo se deja de ser boxeador?

De igual manera, Sugar Ray Robinson, Muhammad Alí, Carlos Monzón, Teófilo Stevenson, Sugar Ray Leonard, Mike Tyson y Evander Holyfield fueron apareciendo en las 91 entrevistas. En total, estuve veintiún días en la región Caribe; para un total de ocho poblaciones visitadas y treinta y tres personajes entrevistados y once días en la zona pacífica, en cuatro localidades y diecisiete entrevistados que se suman a las cuarenta y una entrevistas (y un número igual de charlas informales) que desarrollé en casi catorce meses de observación en tres gimnasios de Bogotá: el del tradicional barrio Olaya, al sur de la ciudad; el del Cayetano Cañizares del occidente bogotano y el principal, ubicado en el Salitre que, retando la opulencia desde su insignificancia, queda contiguo a las dos instituciones políticas más importantes del deporte en Colombia: Coldeportes y el Comité Olímpico Colombiano. Sumando, son casi 75 horas de grabación magnetofónica (itodo un homenaje a Óscar Lewis y a los testimonios y cuentos- casetes de Sánchez Juliao!), 10 de video, 600 fotografías y 9 libretas corrientes de observación. Dos años de mi vida se los he entregado a esta etnografía con la esperanza de hacer una descripción de buena fe, un relato comprensivo y un conjunto de interpretaciones que permitan entender por qué es posible el boxeo en algunas de nuestras comunidades (y, por extensión, en el país) y cómo esas comunidades son posible a partir del boxeo. 
Claro, esa fue la presentación inicial que, como era de esperarse, maduró y varió en el desarrollo del trabajo. Lo más significativo fue que el tiempo de la observación se extendió en tiempo y en geografía: la etnografía se alargó a 14 meses (de 09/2007 hasta 01/2008) y terminó en las costas Atlántica y Pacífica que son los lugares de origen de casi toda la población observada y de los llamados "referentes históricos" del oficio pugilístico. Esa circunstancia motivó que la tesis buscara financiación la cuál se obtuvo de la vicerrectoría académica de la Universidad Nacional, sede Bogotá; a través del programa de apoyo a tesis de maestría del programa HERMES.

\section{Tercer asalto: calzándose los guantes de la investigación}

Ya con el banderazo de partida, por parte del Comité académico y del propio director, había que realizar lo prometido en el proyecto en los tiempos contemplados en el cronograma. Lo primero fue la fase de documentación exhaustiva, las acreditaciones para efectuar in situ, las observaciones y la consecuente entrada en terreno. Ilustrativo resulta, en este punto, compartir las impresiones consignadas en el prólogo de la tesis en cuestión. A continuación tres párrafos que expresan manera vívida los intereses y pasiones del autor, así como los temores que lo asaltaron en el campanazo inicial de la investigación:

Admito que el temor fue la primera sensación que rodeó el comienzo de la presente investigación: estrenarme como etnógrafo, cuestión de por sí intimidante, teniendo como tema de estudio el deporte, específicamente el boxeo que se ha distinguido por la oscuridad de su entorno, era una tarea académica con tinte de desafío atlético que -utilizando términos pugilísticos- implicaba "rifarse en el cuadrilátero" para escudriñar, develar y comprender parte de la vida de los boxeadores que habitan en Bogotá y compiten por esta ciudad a la hora de saltar al tinglado.

Superar la timidez de proponer un tema heterodoxo, que elude las pesquisas asumidas por el canon disciplinar y entrar con el diario de campo en terrenos que carecen de tradición de estudios antropológicos fue una decisión que costó tomar y que aún hoy produce miedos en aspectos como el de la percepción que mis compañeros de maestría, mis profesores y mis colegas, en general, tienen sobre la seriedad y pertinencia del problema que abordo y sobre la forma como he decidido afron- tarlo; para algunos mi trabajo es un escenario inevitable ya que conocen mi delirante afición por el deporte que les hace sospechar de mi objetividad y para otros mi etnografía es una versión a medio camino entre lo literario y lo periodístico; conclusión fundada en mi gusto por la escritura (y por la lectura de géneros como el de la novela negra) y en mi diletante oficio de periodista futbolero. Para los primeros no existe el necesario alejamiento -neutralidad afectiva- con el objeto (sujeto) de estudio ${ }^{5}$ por lo que el presente trabajo de grado puede resultar un panegírico que prescinde de la crítica frente a los evidentes excesos del deporte moderno y para los segundos esta monografía tendría mejor suerte y recibo en un concurso de crónica literaria o en una serie de reportajes de prensa.

\section{Cuarto round: entrando al gym de box}

Miedos y planeación se aplazan cuando se trata de empezar el trabajo de campo. Tomemos de la tesis, el relato de la primera entrada al gimnasio de boxeadores:

Centenares de veces había pasado enfrente del andén del Complejo Deportivo El Salitre y nunca sospeché que adentro hubiese varios gimnasios, en uno de los cuales, varios púgiles reclutados en las costas norte y occidental de Colombia, procuraban ganarse un lugar en el equipo distrital que defendería los colores de la Capital en los Juegos Nacionales. Como a mi, al grueso de la población bogotana, le sería indiferente esa mole de cemento compuesta por el Coliseo de baloncesto, las canchas pavimentadas de microfútbol, las rampas para skateboarding, el diamante de beisbol, las canchas de fútbol, las pistas de atletismo y patinaje y el velódromo ciclístico; como a mi, para los presurosos transeúntes y para los racimos de ciudadanos apiñados en las busetas que transitan la Avenida 68 y la Calle 63, ese espacio es el destinado por la alcaldía mayor para "fomentar el deporte y la recreación", con todo lo huero del término "fomento" y todo lo

\footnotetext{
${ }^{5}$ Esta prevención implica una metáfora: de un lado Orlando Fals Borda (1985) invita a aproximarnos a las comunidades de estudio hasta llegar a estar "cara a cara" en una relación horizontal, sin jerarquías; no obstante, también recomienda el alejamiento para reflexionar sobre la experiencia observadora de convivencia, es decir, el proceso es de proxemia relativa, de Kinesis (movimiento) constante. Así mismo, el deporte del pugilato prevé en sus manuales técnicos el "face to face" para fajarse ante el rival (golpearlo de cerca, en el rostro o el hígado) y la rauda salida -el alejamiento- para estudiar los movimientos del rival y para escapar de su peligroso brazo.
} 
irrealizable que resulten las palabras "deporte" y "recreación" en el virtuoso postfordismo de hoy.

Así es que mi primera sorpresa fue saber que no sólo había un gran salón destinado a la gimnasia, la esgrima, el ajedrez, el yudo, la lucha, el tenis de mesa, los bolos, sino que también había uno dotado de cuadriláteros, espejos, barras de ejercicio, campanas, peras y sacos.

La verdad, el aspecto del gimnasio distrital de boxeo no me impresionó: tuve la sensación de "ya haber estado ahí". Al sumergirme en ese déjà $v u$, evoqué otros "no lugares" que me habían adelantado la visión que tenía delante de mis ojos: el "Mickey's Boxing" (el gym que aparece en las seis películas de Rocky) y el boxing club de la cinta de Eastwood; las fotos y descripciones del gimnasio de Woodlawn de Chicago en el que se sumergió Wacquant; el gym neoyorquino en el que se entrenó "Rocky" Valdéz antes de su debut internacional (ubicado, según el libro de "Meporto", en la calle 28 con 7ma Avenida); el recuerdo oral que le escuché a Pambelé, en la entrevista que le hizo Marlon Becerra en el Canal 7, en el que describía el pobretón coliseo en el que se preparó en Caracas... y las visitas a los sitios de "entreno" de San Basilio de Palenque, Lorica, Santa Marta, Barranquilla, Cartagena, Cali y Buenaventura que me anticiparon la imagen que está enfrente mío: una grasienta sala rectangular, ocupada por dos tinglados elevados a un metro del piso, al fondo de la cual hay cuatro hileras de sacos embadurnados de sudor, alternadas de peras que se reflejan en los desportillados espejos que cubren parcialmente las paredes. Las frases que invitan a la disciplina "sólo el esfuerzo diario nos hace los mejores"; el afiche de un grande (en éste caso el de un púgil, en guardia, que se me parece a Rocky Marciano) y las banquetas recostadas contra la pared del fondo, que sostienen protectores craneales de color rojo y azul; guantes de todos los tamaños y calidades y el intermitente -e insoportable- sonido del timbre que anuncia el fin de otros tres minutos... Todo eso "olorizado" con el penetrante orín de los baños mal aseados [...] (Nota de campo del 8/06/2008).

Es más, que cualquiera, que tuviese dos fotos $3 \mathrm{x}$ 4 , un carné del sisben y pudiese pagar una pensión de $\$ 25.000$ al mes podía inscribirse ¿cómo no supe de esto antes? ¿Cómo no me enteré, en los quince años que llevó en el Distrito Capital, que en ese lote público había cursos de boxeo? [...].

\section{Quinto round: guanteando como etnógrafo}

La etnografía además de registro es sensibilidad para captar detalles con los cinco sentidos y con el sexto de la intuición. Pero no sólo para capturarlos, sino para hacer que nos cuenten cosas que siempre han estado ahí, pero que parecían ocultas por no saber mirar bien. La etnografía es método, campo y reflexividad (Guber, 2001). En el prólogo de la tesis, está dicho en otros términos, de manera más literaria, cuando se dice que...

A continuación está servido todo el menú etnográfico, cuyos platos van desde la descripción densa de la rutina de entrenamiento de un púgil alistado en el ejército de boxeadores que se liarán a golpes con otros pares en procura de una medalla apenas más cara que el latón; desde la viñeta que re-crea la cruda cotidianidad de una gloria nacional, venida a menos, como Pambelé; hasta las entrevistas estructuradas in situ (es decir, a orillas del Atlántico o cerca del Océano Pacífico que es dónde nacen casi todos los boxeadores colombianos) con padres, tíos, abuelos, madres, hermanas, amigas y novias de los deportistas en cuestión. Cocción académica que implicó vivir en medio de sacos, peras, cuerdas, pesas, espejos, tinglados, lonas, guantes y demás trastos y artilugios de la antiquísima disciplina griega reinventada por el Marqués de Queensberry en el siglo XIX; cocido etnológico que invitó -para utilizar una expresión del argot estudiado- a "meternos en la cocina" de los boxeadores para paladear su gastronomía cargadamente marina y que impulsó a visitar comunidades marginadas social y culturalmente: allí convivimos -de forma fugaz, pero significativa- en humildes barrios y modestas casas de ciudades como Bogotá, Santa Marta, Barranquilla, Cartagena, Sincelejo, Montería, Cali, Buenaventura y en populosas barriadas y sencillas moradas de pequeñas poblaciones como Tumaco, San Basilio de Palenque, San Onofre, Lorica, entre otras.

Observaciones directas que permitieron la experiencia vivencial y el progresivo desarrollo conceptual del ambiente natural en el que se mueven, respiran, duermen, comen, festejan, entrenan, combaten, superviven e interactúan doce jóvenes colombianos, todos hombres, once de ellos de tez negra, diez de ellos costeños, todos menores de 23 años; todos pobres y escasamente letrados... en ultimas, esta inmersión etnográfica que nos llevó desde el gimnasio de box del complejo deportivo el Salitre en la Capital del país a la destartalada enramada que oficia como lugar de entrenamiento de Lorica (Córdoba) fue tan aleccionante en lo 
personal como en lo profesional: se asistió -muchas veces de manera pasiva y otras veces de forma activa- a un round de la vida nacional. Esta impactante aventura que hizo que nos enfundáramos unos guantes -emulando al sociólogo Loïc Wacquant ${ }^{6}$ - y sintiéramos la adrenalina previa al sonido de la campana y experimentásemos el coraje natural ante el duro castigo del rival de enfrente fue un vehículo no solicitado, pero si agradecido, para escrutar, auscultar, pensar y repensar buena parte de la idiosincrasia popular colombiana. Este sumergimiento en la vida de doce informantes privilegiados nos condujo -sin preverlo de antemanoa bucear en la cosmogonía del personaje nacional que es a la vez negro, semianalfabeta, de estrato socioeconómico inferior al nivel tres, que sobrevive con máximo un salario mínimo, que de diversas formas padece exclusión social, que es provinciano (más específicamente de las regiones naturales Caribe y Pacífica), que es joven y que practica un deporte: es decir, la caracterización del "sujeto ideal" de la investigación (el entorno de nuestro boxeador promedio) corresponde en su tipificación ¡a la de aproximadamente el $20 \%$ de la población ${ }^{7}$ colombiana!

Todo este voyerismo profundo es un ejercicio antropológico fundamentado en el trabajo de campo -en una etnografía- que busca la construcción progresiva de un "metarrelato" (una versión literaria, en todo caso) en la que se de cuenta del entorno particular y especial en el que coexisten los deportistas en cuestión, a través del intento por satisfacer tres preguntas fundamentales: ¿qué significa ser boxeador?, ¿cómo se fabrica un pugilista? y ¿cuál es la relación entre deportista y territorio y deportista y ciudad? De las que se pueden deducir tres preguntas siamesas que complican la investigación a la vez que la enriquecen: ¿qué significa ser costeño/colombiano?, ¿cómo se fabrica un afrocolombiano? y ¿cuál es la relación entre ciudadanía y territorio y ciudadanía (marginal en todo caso) y ciudad?

${ }^{6}$ Wacquant se inscribió como boxeador en un gimnasio de Nueva York con el objetivo de analizar la división racial y las transformaciones sociales en los barrios relegados; pero lo que no previó este osado investigador era que, según sus propias palabras: "el gimnasio me atraparía y se convertiría en un elemento esencial de mi vida, pero también en un segundo objeto de estudio, deudor de un análisis sociológico propiamente dicho".

${ }^{7}$ El Censo General de 2005 informó que las regiones Atlántica y Pacífica suman dieciséis millones de habitantes aproximadamente y que de ellos el $33 \%$ son hombres menores de 25 años.

\section{Sexto round: antropología, sociología y deporte}

Cómo el deporte se convierte en un tema legítimo de las ciencias sociales en general y de la antropología en particular fue una de las preguntas que originaron una vuelta hacia atrás, a la génesis misma de la disciplina, en dónde se encuentran los fundamentos del oficio: dar cuenta a la Corona Británica del siglo XVIII de las cosmogonías de los "nativos" que poblaban territorios hasta ese entonces ignotos. Una ciencia de averiguación, hermenéutica y en mucho imperialista que, sin embargo, hoy aporta luces sobre los rasgos comunes que nos unen, más allá de los que nos separan que han sido utilizados para tantas infamias. En ese sentido, se rastrearon propósitos centrales de la antropología, así como producciones previas que hayan integrado estudios antropológicos con el deporte. La tarea desde un principio se mostró interesante y útil, pero nada fácil:

[...] era importante efectuar una lectura y una relectura entre líneas de una buena porción de la sociedad colombiana; no obstante, ese propósito debía afinarse y delimitarse: se trataba de echar una mirada sostenida e intensa sobre unos pocos colombianos cuya seña principal era su condición de pugilistas; sin embargo, esa particularidad, esa especificidad no impedía ni obstruía una hermenéutica de la sociedad colombiana en general avalada en el refrán "en lo poco se ve lo mucho" que responde a la cuarta característica, señalada por Clifford Geertz, del trabajo de los antropólogos en comunidades pequeñas (aldeas): el carácter microscópico, la capacidad para elaborar una interpretación general de la sociedad a partir de "los conocimientos extraordinariamente abundantes que [se] tiene de cuestiones extremadamente pequeñas" (Geertz, 1993). En otras palabras: reflexionar sobre la colombianidad, sobre la condición afrodescendiente, sobre la discriminación, la precariedad económica, la juventud y el analfabetismo a partir de una práctica deportiva: el boxeo. Disertar, documentadamente, sobre la política, la economía y la cultura del país desde la política local/personal; desde la microeconomía (economía per cápita) y desde el folclore glocal $^{8}$. Dicha estrategia teórico- metodológica no es original ni inédita: ya Eduardo Archetti (2003) intentó un retrato de la identidad argentina a partir de prácticas arraigadas en la nación gaucha como el tango, el polo y el fútbol y el mismo Roberto Da Matta (1982) llegó a sentenciar que el Brasil

\footnotetext{
8 Término acuñado, a finales de 1989 , por Manfred Lange para significar la presencia de lo local en lo mundial y viceversa.
} 
con mayúscula se haría conocer en todo el orbe por la samba, el Carnaval de Río de Janeiro y por lo que la prensa internacional conoce como el "jogo bonito” de su selección nacional de fútbol.

Así las cosas, habría que hacer justicia diciendo que si bien los estudios sociales (sociológicos y antropológicos, sobre todo) del deporte son escasos, existen importantes estudios en Europa y América que aluden "el campo" deportivo de forma tangencial (Ortega y Gasset, por ejemplo, refiere el origen del Estado al deporte [1966] y Hobsbawm señala la importancia del deporte en la construcción de los nacionalismos "desde abajo" [1990]) y otros, los menos, que hablan del y desde el deporte. Dicha situación de orfandad denunciada primero por Norbert Elías (1992) y luego por Umberto Eco enfatiza el desdén de la ortodoxia académica para cubrir temas que en apariencia son "géneros menores" (Eco, 1978), porque siendo temas de interés masivo no encuentran espacio apropiado en la organización académica por no considerarse dignos de una tradición.

Tal aprehensión hacia temas como el deporte va disminuyendo ${ }^{9}$, no obstante aún subsisten rezagos que parecieran rotular los objetos/sujetos de investigación en "importantes" e "inocuos", emulando la polarización que la Escuela de Frankfurt hiciera de la "alta cultura" y la "cultura vulgar" que es la génesis de cierto tipo de divisionismo, casi extinto en las universidades de hoy día, que calificaba las disciplinas académicas en dos bandos: "las duras" (ciencias exactas y aplicadas) y las "blandas" (ciencias sociales y humanas); segmentación que aludía al posicionamiento y la legitimidad de unas ciencias sobre otras; situación controvertida por algunos investigadores del último tiempo como Pablo Alabarces quien afirma que si bien estudios como los del deporte ayudan a "leer operaciones de tipificación que colaboran en las dificultosas construcciones de las narraciones identitarias" todavía están en la "periferia de lo legítimo (porque el lugar central seguirá siendo de la cátedra o la política o los medios, según su capacidad históricamente variable de instituir y administrar legitimidades del discurso)" (Alabarces, 2004).

Entonces lo que tenemos aquí es una etnografía sobre un tema emergente, pero dicho tema no es el fútbol y ello presenta otro problema: excep-

\footnotetext{
${ }^{9}$ Un buen indicador es el creciente número de monografías en el nivel de pregrado que, en la Universidad Nacional de Colombia, tratan temáticas directas o relacionadas con el deporte.
}

tuando el libro Entre las cuerdas: cuadernos de un aprendiz de boxeador de Loïc Wacquant (2006) y el ensayo Del boxeo de Carol Joyce (1990) no existen estudios socio antropológicos del boxeo; claro que esa aseveración puede ser aventurada y hasta irrespetuosa si consideramos que desde el siglo VI a.C. existe, con Homero, literatura sobre el particular. Si suponemos que obras como las de London (2000), Faulkner (2008), Hemingway (2003), Cortázar (2004), Mailer (2005), Aldecoa (1995), Hazlitt (2005), Lardner (1984), Talese (2008) y Fontanarrosa (2004) son de poca monta o espurias de las ciencias sociales; si desconocemos que los rigurosos y concienzudos estudios de la sociedad de hoy provienen de la novela romántica y realista de autores del diecisiete, dieciocho y decimonónicos como Tolstoi, Zola, Víctor Hugo, Balzac y Dickens [...].

\section{Séptimo round: literatura, periodismo, antropología y boxeo}

La declaración de "ausencia de fuentes" es la marca de los pioneros, afirma Alabarces (2004), por ello, ante el desierto de textos científicos sobre el tema, hubo que echar mano de otros de naturaleza espuria que si abundaban, aunque su eugenesia fuese discutida. Narrativas de literatos y de periodistas suplieron la orfandad, contribuyendo de manera decisiva no sólo en la comprensión del mundo boxístico y en la detección de sus imaginarios y representaciones sociales, sino en el cariz mismo de la tesis. A propósito de esa evidencia, esto quedó consignado en la tesis:

En efecto, la literatura ha enriquecido y, en gran medida, mitificado el oficio pugilístico; acrecentando el aura sórdida y misteriosa que le es natural (la del "bajo mundo del box"), creando personajes sospechosamente ficticios como: El Amo de Croxley, Tom King, El Mexicano Rivera, Paco Young Sánchez, Midge Kelly, Jack Brennan, Ole Andreson, Ad Francis, Robert Cohn, Torito, Roberto Esteban, Rafael Montalbán y en el ámbito nacional: Celestino Estévez "Kid Ligero" y Fercho Durango "El Flecha"; cuyas verosímiles historias nos hacen dudar que no existieran (o que no pudieran o merecieran vivir) y recreando figuras iconográficas de talla mundial como John Sullivan, Jack Dempsey, Luis Ángel Firpo, Joe Louis, Jake la Motta, Mantequilla Nápoles, Carlos Monzón, Sugar Ray Robinson, Georges Foreman, el gran Muhammad Alí, "Mano de Piedra" Durán, Mike Tyson y "Kid" Pambelé.

Al detectarse esa inexcusable ausencia de la 
universidad y su entorno crítico ¿qué de distinto puede reclamársele a la literatura que no sea su mayor presencia en este deporte? ¿Podría culparse al mundo de las letras por cumplir su objetivo misional de recrear su entorno? ¿Son del todo equivocados los retratos de época y de sociedad que Conan Doyle (1964), Wodehouse (1981), Garibay (1979), Soriano (1983 Rodríguez Feu (2000, 2003), Palou (2003), Toledo (2005), de la Rosa (2008), Pérez Domínguez (2008) y David Torres (2008), hicieron a través de sus vívidos relatos boxísticos? Corolario de esa triada de preguntas es el siguiente interrogante ¿Qué sería del boxeo sin la literatura? del que se desprende una interrogación más fina y más obvia: ¿qué sería del hombre sin las letras?

Aquí no se pudo resistir la tentación de decir que si bien la antropología se nutrió en sus comienzos con historias fantásticas fabuladas y recreadas por plumas como las de Conrad ${ }^{10}$ (1983, 2002), Stevenson (1982, 1999), Salgari (1982, 1989, 1998), Defoe (1970); e inclusive de Scott $(1984,1985)$ y Alejandro Dumas (1984); el deporte tiene en la crónica periodística y el boxeo en los cuentos y novelas de grandes autores, espléndidos referentes para acometer con mayor contexto sus abordajes investigativos.

¿Qué sería del excepcional combate entre Alí y Foreman, en Kinshasa 1974, sin la pluma de Norman Mailer? Probablemente esa descarnada pelea no se hubiera borrado del imaginario público ya que para entonces la televisión ya existía y ya había probado los jugosos réditos que proporciona el deporte, pero -de eso estoy seguro- la sociedad estadounidense jamás se hubiera llegado a cuestionar, de manera tan acertada, sobre su moderna barbarie massmediática, sobre sus exacerbados niveles de consumo, sobre su segregacionismo racial, sobre su desmesurada violencia simbólica sino fuese por la brillante narración literaria (exul-

${ }^{10}$ Existe una corriente académica denominada "antropología poética" que privilegia la textualidad al definirla como parte de un proceso transdisciplinario que pretende la desestructuración de algunos sectores del canon antropológico actual, de las ciencias sociales positivistas y, en general, del discurso de la modernidad. Dicha corriente se acerca a determinados creadores literarios como Jorge Teillier; escritores mapuches como Elicura Chihuailaf o Leonel Lienlaf, europeos como Joseph Conrad, investigadores como el P. Martín Gusinde o Carlos Castaneda, que han superado o transgredido dicha tradición. Esta tendencia coincide en algunos aspectos con el ademán rupturista de los sectores intelectuales considerados como posmodernos en los países centrales, y posmodernos periféricos en los demás (Carrasco, 2003). tante relato etnográfico) del doble ganador del Premio Pulitzer; sin el recién desaparecido Mailer.

Por todo eso, este trabajo monográfico está preñado de literatura por doquier y esta impregnado de altas dosis de periodismo lo cual le da algo de razón a quienes esperan de él un producto literario y/o periodístico. Literatura y periodismo que se configuran como herramientas metodológicas $\mathrm{y}$, a la vez, como fuentes documentales; de hecho después de leer los célebres autores citados a los que se sumaron plumas del ámbito nacional como David Sánchez Juliao (1985), Andrés Hoyos (1994) y Alberto Salcedo Ramos (2005), una de las tareas asumidas fue proceder a examinar la prensa nacional (repitiendo la faena que en igual sentido hizo el citado Archetti con la revista deportiva "El Gráfico" de Argentina, específicamente el monopólico diario El Tiempo y su sección de Deportes de la última década (1997-2007) para observar la presencia del boxeo en las noticias de Colombia y de qué calidad es la presentación de este deporte a la opinión pública nacional (a la comunidad lectora). También es justo reconocer que el cine "se metió al cuadrilátero" de esta tesis: 15 películas de boxeo fueron analizadas sin impunidad alguna; las influencias y desarrollos de "Luces de la ciudad" (1931), "La ley del silencio" (1954), "Más dura será la caída” (1956) y "Toro salvaje" (1980), entre otras, se expresan aquí no sólo a nivel documental, explicativo e interpretativo, sino en la estética de la escritura que -de párrafo en párrafo- opta por el guión cinematográfico más que por el reporte etnográfico.

\section{Octavo round: capítulos de la investigación, otras artes y otras fuentes}

El boxeo: un deporte marginal dentro de un género menor o una práctica alucinante en donde el estereotipo es superado por la realidad, fue el título del prólogo A manera de excusa. El primer capítulo fue bautizado La literatura y el periodismo como guantes de esta pelea. El segundo: Antropología, periodismo, literatura, cine y boxeo, y el tercero: La etnografía como tal, ambición, estereotipo y gloria: boxeando con al vida. Una mejor explicación de estas divisiones está en el propio prólogo del investigador, escrito el 13 de abril de 2009, en donde dice:

El presente combate académico se divide en dos rounds separados por el minuto de descanso (el entre rounds): el primero es un ensayo sociológico, un artículo si se quiere, en el que subo al ring algunas contribuciones de la literatura, particularmente la llamada "novela realista" del XIX y principios del $\mathrm{XX}$, a la disciplina antropológica y, luego, a la etno- 
grafía. En esa pieza sociológica me esmero por ilustrar los puntos en común entre el "arte de escribir" del literato (novelista) y el etnógrafo (observador social). El entre rounds versa sobre la dialéctica existente entre el binomio antropología-etnografía y el periodismo, especialmente el "nuevo periodismo" que originó audaces estilos como el "periodismo gonzo", el "periodismo border" y la "non fiction novel". Aderezo ese entremés con unas gotas de cine que ilustran el mundo boxeril con una plástica documental para nada desdeñable. En el asalto final se busca despachar por "la vía rápida", el nocaut, la etnografía propiamente dicha. Pero el nock out no implica comodidad y facilismo, al contrario, él es la maniobra excelsa del box; por ello utilizo esta metáfora que espero se compadezca con el producto etnográfico presentado. Al final habrá un esforzado apéndice bibliográfico, en el que incluyo una "boxeografía", una "púgilteca" y un agregado de "boxingmusic" con los hallazgos literarios, cinematográficos y musicales alusivos al noble arte.

\section{Noveno round: el escurridizo Pambelé y la imprevisible casualidad}

Este trabajo fue una serendipia total: una pesquisa llevó a otra en un juego interminable de pistas, cabos sueltos e indicios que el profesor Pineda, director de la tesis, forzó a clausurar invocando la sentencia de Borges de "publicar para dejar de corregir". También fue alentador constatar que la tesis coincidiera, a grandes rasgos, con la formalidad y el tono del libro de Wacquant: obra que llegó a manos del investigador sobre el final del trabajo monográfico. No obstante, también hubo frustración; sentimiento que es consustancial a la ambición: nunca se alcanza lo deseado y la academia no es la excepción. Difícilmente un texto estará a la altura de las expectativas del autor. Con el agravante de que existen sinsabores de menor valía que igualmente causan desazón en los investigadores. Para la muestra un botón: no se pudo realizar la entrevista al boxeador por antonomasia de Colombia. Siempre Pambelé se escurrió por segundos y sus evasivas fueron consignadas en el documento final:

Don Edimir Navarro me sorprendió: estaba esperándome en la portería del instituto, para regalarme un libro de Miguel Gómez, sobre la vida de Pambelé. Le había hecho conocer a todo el mundo el tema de mi tesis. Ello había provocado varios hallazgos: el desconocido libro El cóndor del ring de Meporto, sobre la vida de Rocky Valdéz, fue resca- tado de las garras del moho, en una desordenada biblioteca, de un colega de la Universidad Pedagógica Nacional que, en una tertulia, recordó su posesión y se atrevió a buscarlo para ponerlo en mis manos. Así ocurrió con los datos de los libros de Irusta, Gay Talase y Salcedo Ramos y con casi todos los cuentos de boxeo que me fueron llegando por vías distintas, en diferentes formatos: por e-mail, fotocopias, señas bibliográficas y, en el mejor de los casos, en la versión original como ocurrió con el libro de Wacquant que fue rastreado - hasta conseguirse- por medio país por mi esposa, ya que a Colombia sólo arribaron dos ejemplares. Incluso el desconocido cuento Kaos de Andrés Hoyos, el único del género junto a El Flecha de David Sánchez Juliao, fue encontrado de una manera curiosa: un librero que yo había visitado para preguntarle "¿qué cuentos colombianos conoce de boxeo?" se puso, después de mi pregunta a indagar y confeccionó una parca lista -que incluía historias de otros países- y la "colgó" en su blog personal ¡que tuve la fortuna de leer hace 20 días! Esas son las pequeñas satisfacciones del investigador.

Así también llegaron a mis oídos decenas de historias: "mi papá fue boxeador" me dijeron dos compañeros de trabajo y una de ellas desprendió el marco de una hermosa y añeja fotografía, colgada en su sala, para regalármela. En la instantánea, el papá de Lida Cruz posa con sus guantes en guardia, mientras es acicalado por su "segundo de a bordo".

Sin embargo, la situación que más me asombró fue la dificultad para dar con Pambelé. Dos veces, sin buscarlo, estuve a punto de topármelo y dos veces que fui "a por él" porque "era seguro" que lo hallaba, se esfumó como agua entre los dedos.

Libre de los compromisos del gimnasio, de la dictadura de la dieta, Pambelé se tiró al desastre. De repente, parecía haber adquirido el don de la ubicuidad. Un día lo expulsaban de un bar de Manizales por haber bailado desnudo sobre la barra y, cuando aparecía en Pasto con el rostro ensangrentado por negarse a pagarle a un taxista (Salcedo

La primera vez que supe de él fue a través de un vendedor de revistas de segunda en la calle 19 , entre carreras $10^{\circ}$ y Caracas, en el centro de Bogotá. Cuando le pagaba una bien conservaba Revista Cromos, de 1976, en cuya portada aparecía el "Kid", el dependiente me despachó la información: "Pambelé acaba de pasar. Vio la revista y me la encargó, pero yo sé que con él eso es perdedera de tiempo" 
-“¿Por dónde cogió”?- le pregunté emocionado. Me señaló la dirección y me recomendó "vaya a la plazoleta de las Nieves que él siempre se la pasa allí en horas de almuerzo". Corrí hasta allí y un chacero me dijo: "justo hoy no ha venido". Pensé que me estaba tomando el pelo, volví sobre mis pasos y olvidé el asunto.

En un restaurante de Cartagena le vaciaron una olla de sopa hirviendo en el pecho y en el aeropuerto de Bogotá le rompieron la frente con una tranca. En Barranquilla le pegaron con un tacón puntilla por limpiarse las manos en el vestido de un maniquí. En Cali, un ganadero le ofreció un mazo de billetes con tal que se fuera rápido de la plaza de toros. Se volvió un inquilino asiduo de calabozos y hospitales (Opus, cit: 26).

La segunda vez fue en la Navidad de 20072008. Estábamos viendo el alumbrado bogotano en la Plaza de Bolívar con mis padres (venidos de Villavicencio), con mi mujer e hija, cuando un revuelo se tomó el lugar: Antonio Cervantes, impecablemente vestido con un traje sastre gris, atendía raudamente los saludos de los adultos que lo identificaban. Me acerqué a él, le tendí la mano y solté la frase menos original del mundo " ¿cómo vamos campeón?" -"todo bien"- me dijo y me lanzó un suave gancho de izquierda que agradecí profundamente. Cuando reaccioné Pambelé ya abandonaba la Plaza sin mostrar ganas de detenerse nunca jamás. Además yo andaba de guía turístico. Otro día sería.

La primera vez que lo busqué en serio, me tomé el asunto a pecho: viajé hasta Medellín en dónde me habían informado que hacia su tratamiento de rehabilitación de la narcodependencia. El viaje era la continuación de una expedición a la Costa Caribe en procura de visitar su tierra natal: San Basilio de Palenque y otras poblaciones como Montería, San Onofre, Lorica, Sincelejo y las ciudades de Santa Marta, Barranquilla y Cartagena. Le seguía la pista al boxeo y la pita me llevaba a él, pero la suerte no me acompañó y mi proverbial torpeza ayudó mucho en ese despropósito: desde la Terminal de Medellín llamé a la "Fundación La Luz" presentándome como estudiante de Maestría de la Nacional. Me dijeron que llamara a las nueve de la mañana para acordar la cita. Esperé con impaciencia y llamé a la hora en punto...

--Señor Quitián, ¿ud. es periodista de qué medio?

-Vacilé (yo no me había presentado como periodista, pese a que si trabajo con un periódico),
--No. Yo soy estudiante de la Nacional, estoy haciendo un trabajo sobre el boxeo...

-Disculpe, señor, pero para esas investigaciones debe hablar directamente con el director de la fundación que, justo a ésta hora, debe estar volando para Bogotá

--Pero ustedes me dijeron

-Le entendimos que era periodista

--Pero yo también soy... (Colgaron) (Escena del 14/11/2008).

¿Qué paradoja? En nuestro país a veces pesa más "la chapa" de periodista que la de etnógrafo. Cosas de la vida. Una lección más.

Llegó un momento, incluso, en que lo veían aunque no lo vieran. Fantasma de sí mismo, un día fue dado por muerto en Radio Sucesos RCN. Cuando apareció indignado por la noticia, hubo gente que no le creyó que, en efecto, seguía vivo (Opus, cit, p. 26).

\section{Décimo round: boxeo, no fútbol + invitación}

Tratar el tema del "rey de los deportes", el fútbol, hubiera sido más sencillo: él ya es un "deporte hegemónico" en términos bourdianos y se cuentan por docenas los libros y estudios existentes, particularmente en lo que respecta a la violencia en los estadios y fuera de ellos, entre fanáticos de uno y otro equipo en lo que se ha bautizado como el "fenómeno de los ultras o del hooliganismo" que naciendo en Inglaterra, tiene réplicas sui generis en Europa y Latinoamérica conocidas como el problema de las barras bravas. No obstante, todo lo que enmarca la tesis de referencia se ha empeñado, sin llegar a ser iconoclasta, en ir contra la corriente al ser, en cierta medida, contrahegemónicos, por ello y por gusto propio escogimos un deporte menor, un deporte misógino (las mujeres desaparecen, según testimonios recogidos en ésta etnografía, cuando se acerca un combate porque "restan fuerza"), un deporte homoerótico (se exalta y se admira el cuerpo masculino, así sea el del adversario), deporte de negros, pobres y excluidos; un deporte marginal, nocturno, de casino, de apuestas, trampa y mafia; un deporte con altos grados de azar porque un buen golpe -de la fortuna- te puede izar en el paroxismo de la gloria nacional o te puede enterrar en las pailas del quinto infierno de la miseria y el olvido; un deporte "políticamente incorrecto" que a pesar de su origen noble y aristocrático, provoca aversión y hasta repulsión en muchos sectores de la sociedad y que hizo que tribunas privilegiadas, 
otrora divulgadoras de su práctica, le hayan vuelto la espalda como sucedió con el diario El País de España que lo rebajó al sub nivel de la fiesta brava cuando en el cuarto artículo de su manual de ética periodística lo proscribió indefinidamente de sus páginas.

Por todo ello y por ser uno de los pocos deportes del mundo en el que la violencia no se sublima ni aparece de forma simbólica (como no sea en "esa pequeña muerte" que es el nocaut), que es el principio excelso del deporte moderno (Coubertin, 1959), sino que es real, hasta el punto de producir lesiones irreversibles, como el mal de Parkinson que padece Muhammad Alí, y en muchos casos la muerte inmediata sobre el escenario o, gradualmente, en la convalecencia de una cama de hospital, es que urge volver nuestra mirada sobre esta humana manera de existir; es que apremia hacer un round de estudio para luego ponerse en guardia ante las sorprendentes arremetidas que la vida de los boxeadores nos arrojan al rostro, ya no como jabs de izquierda, sino en forma de reveladoras lecciones académicas y de vida.

Esa es la invitación que se hace a los lectores del artículo: que se quiten los guantes de la prevención, que se despojen del protector pélvico y bucal, que desnuden su alma, su pecho y extremidades y se suban al caluroso ring de la vida y se permitan boxear, al menos un rato, hasta que suene la campana o hasta que un imprevisto golpe de la vida los noqueé; que se permitan besar la lona, saborear la agridulce savia de la derrota para ponerse en los zapatos ¿o en los guantes? de estos incansables buscadores de triunfos que, de verdad- verdad, se ganan la vida a puño limpio, recibiendo día tras día puñetazos del destino y llenando, en cada sudorosa jornada, su cuerpo y su alma de marcas indelebles que significan más que el estereotipo de las narices chatas, porque son la forja esculpida por una sociedad ilusoria, que auspicia la ilusión de progreso y éxito sobre la permanencia de profundas desigualdades sociales.

\section{Décimo primer round: el nocaut de las conclusiones}

Para cerrar esta reseña ilustrada de una investigación antropológica sobre boxeo, compartimos un trozo del capítulo final de la tesis, en el que se ejemplifica la propuesta de escritura de la tesis y en dónde se adelantan conclusiones de la observación:
Estoy convencido que de haber nacido en Cartagena de Indias hoy mismo sería boxeador. No digo campeón del mundo, pero si boxeador ¿qué hubiera necesitado para serlo? Nada. Bastaba con el registro civil y listo... bueno, también sería necesario ser criado allí y no ser mujer, por supuesto. Si mi madre hubiese decidido tenerme en "La heroica" yo habría desarrollado ese ritmo, esa cadencia, esa sabrosura para caminar que tienen todos los bolivarenses y, en general, todos los costeños. Sabrosura legendaria, expresada en las letras de Candelario Obeso, Jorge Artel, Cépeda Samudio y Gómez Jattin; en la música de Alejo Durán, Lucho Bermúdez y Rafael Escalona, en la precocidad política y el orgullo étnico del Presidente Nieto; en la severidad mística de Úrsula Iguarán y el pragmatismo utópico de José Arcadio Buendía y en la frescura socarrona de El Flecha y El Pachanga, "Gallito" Ramírez y el mismo Fercho Durango.

Total que el viejo Deibi nos agarró en la jugada. Ñerda y me mandó a mí a salir al tablero a hablar de los egipcios. Me acuerdo que salí yo caminando así, lentamente, con caminadito de beisbolista, nalguitapará, como cuando van pal home, y cejitas alzaítas de detective de película mejicana. Y llegué al tablero y me le cuadré y le digo: "dígame viejo profe", y me dice: "bueno, Durango, hábleme de los egipcios". Y le digo: "mierda, mi viejo Deibi, ¿los egipcios?". Y me dice: "sí, los egipcios". "Bueno, los egipcios eran unos manes legales, sabe". Y me dice el viejo Deibi: ¿y en qué consistía la legalidad egipcia? Y digo yo, "bueno, en que esos manes, nojoda, hacían unas pirámides tablúas, sipotúas, del porte de la house que le voy a hacer yo a mi mother cuando sea Champion, sabecomo'e" (Sánchez-Juliao, 1981, p. 53).

Sabrosura que es condición sine quanon, como dice el corpulento entrenador Abel Cassiani, para subirse a un ring de box. Si mi mamá me hubiese parido en la ciudad de Rafael Núñez, pero también de Bernardo Caraballo y Rodrigo Valdez, yo habría madurado esa capacidad de resistencia al yugo y a la muerte que los Turbacos demostraron ante el ibérico Juan de la Cosa (quien murió asaeteado por los indígenas en 1509), que los palenqueros -como lo canta Joe Arroyo- esgrimieron ante los colonizadores españoles y que los cartageneros -como lo escribe García Márquez- emplearon en el asalto del pirata Francis Drake y ante el asedio asesino del realista Pablo Morillo.

Si yo hubiese visto la luz del mundo en el "Corralito de piedra", seguramente asistido por una partera, habría comido todo el sábalo (un pez rico en músculos y sabor, para algunos el mejor del mundo) requerido para fortalecer mis bíceps y cuádriceps y habría endurecido, con ñame, cari- 
mañolas, butifarras soledeñas y mote de queso con leche de coco, mis abdominales y pectorales. Si yo hubiese nacido en el rústico tugurio de Chambacú, "Corral de los negros", según Manuel Zapata Olivella (Porto, 1978, p. 48); villa miseria de donde es el campeón de los medianos Rodrigo Valdéz y en dónde se crió El Benny Caraballo, primer colombiano que peleó por un campeonato mundial ó si hubiese crecido en inmediaciones del Cerro de la Popa, del Parque Centenario, del mercado Bazurto y de ese fortín de la Independencia criolla que es Getsemaní, habría visto el boxeo como una opción de vida. Si hubiese sido vendedor de pescado como Fidel Bassa o lustrabotas como Caraballo y Antonio Cervantes, habría tenido el chance de beber el suero costeño necesario para enriquecer mi sangre y espesar mi saliva; habría engullido todo el bollo e' yuca y las arepa e' huevo indispensables para templar mis brazos y acerar mis piernas. $\mathrm{Si}$ mi mamá me hubiese parido en el litoral atlántico colombiano yo podría tener la piel negra, embebida en melanina, que es requisito fundamental para ser de la égida de Joe Louis, Muhammad Alí, Mario Rosito y de Antonio Herrera; pero también es condición obligatoria para bailar currulao, cumbia, porro, bullerengue, puya, champeta y para danzar en el cuadrilátero y noquear rivales...

David Quitián: ¿se puede decir que hay una manera nacional de boxear?, es decir, si a alguien que no conoce de boxeo, se le presentan boxeadores o pugilistas colombianos, ¿podría él identificar un rasgo común del colombiano para boxear, así como puede distinguir uno de un cubano; eso es susceptible de percibirse?, ¿existe una manera cubana o panameña de boxear?

Raúl Porto Cabrales: bueno, fíjate, el boxeo es sinónimo de ritmo, ritmo, el boxeador que no tenga ritmo no sirve para boxeador. En el boxeo se conjuga una serie de movimientos naturales, movimientos de piernas, de tronco, de cabeza, de cintura, de brazos, o sea, un boxeador nato es ese, el que tiene movimiento [...] típicamente yo te puedo decir que un boxeador es un buen bailarín, el que no sabe bailar no puede ser boxeador jjamás! no despega los pies del piso y ese ha sido el problema en el interior del país: el boxeador del interior del país pelea con los pies pegados a la lona, ese nunca puede surgir, nunca llega, porque lo cogen mal parado y un golpe lo revienta, no sabe retroceder, no sabe cabecear, no sabe mover la cintura, el tronco, son cosas naturales eso no es que..., ahí pueden perder el tiempo cien mil años enseñándole y no sale, no sale, porque eso es cuestión yo creo que genética o algo así por el estilo (Entrevista del 9/05/2008).
0 , como se ve, podría ser pelotero. Oficiante del deporte más importante y exclusivo del Caribe; bateador de las grandes ligas como Orlando y Holbert Cabrera. Practicante del beisbol que es, entre los deportes, el más resistente a la globalización del espectáculo: su geografía se reduce a poco menos de la mitad de América y a una sección más bien reducida de Asia. De haber sido cartagenero no me llamaría como me llamo y mis amigos, conocidos y admiradores tampoco me llamarían como mi madre me hubiese bautizado (sin consentimiento de mi padre, que seguramente nos habría abandonado): me dirían "Rocky", "Mochila" o "Pambelé".

-Pero no nací allá y por esa casualidad del destino soy etnógrafo y no boxeador-

\section{Sintéticamente, estas fueron las conclusiones:}

- La manera de escribir de los antropólogos puede ser, a la vez, un tema de investigación y un método de escritura. La preocupación por la forma, decía Geertz, es -a la larga- una preocupación por el fondo.

- La novela naturalista y realista, de los siglos XVIII y XIX, son contribuyentes de la antropología en general y de la etnografía en particular. Ambas cosas, literatura y descripción antropológica son artificios. Da lo mismo Madame Bovary de Flaubert que cualquiera de Los hijos de Sánchez de Lewis.

- El periodismo, en sus novedosas expresiones del "nuevo periodismo" y el "periodismo Border" es muy cercano a la "nueva etnografía" y a "la antropología simbólica”: el autor está siempre presente y la "objetividad" queda desplazada por la veracidad y lo que García Márquez llamada la "verosimilitud".

- El deporte, como casi cualquier tema, es un asunto de la antropología. Una cosa es no tener tradición de estudio y otra, muy distinta, es no gozar de legitimidad.

- Dentro del "género menor" (como llamaba Umberto Eco a temas de poca o nula tradición, en ciencias sociales) del deporte, el boxeo es, a su vez, un subgénero. La hegemonía en estudios siempre la ha tenido el "deporte rey": su majestad el fútbol.

- Hollywood y el Star System, así como la literatura, han acogido al pugilato como tema predilecto: grandes directores y excelsos escritores (vale decir que también autores mediocres lo han hecho) escenifican sus historias en ambientes boxeriles o con protagonistas boxeadores. 
La razón es el innegable agonismo que subyace en ésta práctica: siempre se está exponiendo la vida y "siempre se está a un golpe de la gloria", lo cual comporta actitudes extremas que son la pimienta para cautivar a las audiencias.

- A través del boxeo se puede observar a la sociedad. Es un punto privilegiado de mira. Así lo ha hecho la literatura y el cine. Así también lo hizo Loïc Wacquant (artífice, hasta ahora, del único experimento antropológico en la materia) quien efectuó una comprensiva mirada del gueto negro de Chicago, realizando una etnografía con boxeadores. No es que se haga "antropología del boxeo" es que a través del boxeo se hace antropología.

- El boxeo, antes que fuese convertido en deporte en el siglo XIX (por personajes como el marqués de Queensberry) es una práctica milenaria asociada a lo sagrado y a la preparación marcial. Sin embargo, existen evidencias de prácticas corpo-culturales, cercanas al box, que tienen un objetivo integracionista y de fiesta; el caso más ilustrativo es el de San Basilio de Palenque y, por extensión, las rondas infantiles de niños peleando entre sí, sin un móvil violento, en las barridas de la costa caribe colombiana.

- El box es una práctica corpo-cultural sui generis de la costa caribe de nuestro país: no es que el boxeo sea un invento caribeño ni que no haya boxeo en el resto del territorio nacional; lo que ocurre es que boxear es más que un deporte en el Caribe, es un oficio con estatus que otorga "un lugar en la sociedad" y da "un sentido de vida" a sus practicantes.

- Un buen indicador del fervor del boxeo en la costa caribe (en contraste, por ejemplo de la otra costa: la pacífica) es la supremacía de esa región en los torneos nacionales aficionados. De igual manera, 28 de los 33 campeones del mundo que ha tenido Colombia son del litoral norte.

- En Bogotá no existe boxeo: hay boxeadores, pero no existe una "cultura del boxeo"; marginalmente hay pugilistas nacidos en el Distrito Capital que boxean, pero fueron hechos en la costa o son orientados por costeños. De contera, toda la selección bogotana de boxeo está integrada por costeños del litoral atlántico colombiano.

- Pese a que la ortodoxia indica que el pugilato es una práctica masculina existe, en el caribe, un importante número de boxeadoras y en poblaciones como el palenque de San Basilio es normal que ellas participen en los festivales de peleas comunales. No obstante, subyace una creencia muy fuerte en el medio de los boxeadores, que ve en las mujeres a la némesis del boxeo: ellas quitan fuerza y concentración. Ello provoca una fase de "homoerotismo" en los pugilistas que están preparándose para un combate.

- En Colombia, con respecto al boxeo, la realidad suele copiar el estereotipo: no es que haya que ser negro, pobre, analfabeta y costeño para ser buen boxeador: es que todos los buenos boxeadores ¡son negros, pobres, analfabetas y costeños!

\section{Referencias}

Alabarces, P. (2004). 'Entre la banalidad y la crítica: perspectivas de las ciencias sociales sobre el deporte en América Latina'. En Memoria y civilización. Anuario de Historia de la Universidad de Navarra, Vol. 7.

Archetti, E. (2003). Masculinidades. Fútbol, tango y polo en la Argentina, Buenos Aires, Antropofagia.

Balzac, H. (1982). Eugenia Grandet, Bogotá, Oveja Negra.

Borda, F. (2002). Historia doble de la Costa, Bogotá, Tomos 1 y 2, Universidad Nacional de Colombia, Banco de la República y El Áncora Editores.

Caicedo, A. (2002). Angelitos empantanados o historias para jovencitos, Bogotá, Norma.

Capote, T. 2006. A sangre fría, Barcelona, Anagrama.

Conrad, J. (2002). El corazón de las tinieblas, Madrid, Alianza Editorial.

Cortázar, J. (1996). Rayuela, Buenos Aires, Alfaguara.

Coubertin, P. (1959). Memorias Olímpicas, Frankfurt, Limpert.

Da Matta, R. (Comp.) (1982). O universo do futebol: esporte e sociedade brasileira, Río de Janeiro, Pinakotheke.

Defoe, D. (1970). Robinson Crusoe, Navarra, Biblioteca Básica, No. 30, Salvat.

Dickens, C. (1982). Tiempos difíciles, Bogotá, Colección Historia Universal de la Literatura, No. 6., Oveja Negra.

Dumas, A. (1984). Los tres mosqueteros, Bogotá, Oveja Negra.

Eco, U. (1973). Diario Mínimo, Barcelona, Ediciones Península.

Elias, N. \& Dunning, E. (1992). Deporte y ocio en el proceso de la civilización, México, FCE.

Geertz, C. (1989åa). 'Descripción densa: hacia una teoría interpretativa de la cultura'. En La interpretación de las culturas, Barcelona, Gedisa, 19-40.

Geertz, C. (1989 ${ }^{\mathrm{b}}$ ). El antropólogo como autor, Barcelona, Ediciones Paidós.

Gómez, G. (2001). La violencia en el fútbol vista a través de las barras bravas, Bogotá, Tesis presentada como requisito para optar al titulo de sociólogo, Universidad Nacional de Colombia. 
Guber, R. (2001). La etnografía: método, campo y reflexividad, Bogotá, Norma.

Hobswaun, E. (1990). Naciones y nacionalismos desde 1780, Barcelona, Crítica.

Lewis, Ó. (2004). Antropología de la pobreza: cinco familias, México, FCE.

Malinowski, B. (1975). Los argonautas del pacífico occidental. Un estudio sobre comercio y aventura entre los indígenas de los archipiélagos de la Nueva Guinea melanésica, Serie universitaria, Barcelona, Península.

Ortega y Gasset, J. (1966). 'El origen deportivo del Estado Obras Completas'. En Revista de Occidente, Madrid.

Pardey et al. (2001). 'La ciudad de los fanáticos: aproximación al fenómeno de las barras de fútbol locales Barón Rojo Sur y Frente Radical Verdiblanco entre los años 1999- 2001'. En La Palabra, Cali.

Pineda, R. (2000). Holocausto en el Amazonas, una historia social de la Casa Arana, Bogotá, Espasa.

Salcedo, M. \& Rivera, O. (2007). Emoción, Control e Identidad: las barras de fútbol en Bogotá, Bogotá, ICANH.

Salgari, E. (1998). Los cazadores de focas de la bahía de Baffin, Madrid, Unidad Editorial.

Scott, W. (1984). Ivanhoe, Bogotá, Colección “Grandes Aventuras", Oveja Negra No. 22.

Stevenson, R. (1999). En los mares del sur, Barcelona, Ediciones B, S.A.

Swift, J. (1975). Los viajes de Gulliver, Barcelona, Bruguera.

Weber, M. (1997). Economía y sociedad, Bogotá, Colombia Reimpresión en español.

Zola, É. (1976). Teresa Rasquin, Barcelona, Editorial Cedro.

\section{Boxeografía (textos de box)}

Aldecoa, I. (1995). 'Young Sánchez'. En Cuentos completos, Madrid, Alfaguara.

Conan-Doyle, A. (2007). Relatos de cuadrilátero, Buenos Aires, Editorial Caridad.

Cortázar, J. (2004). 'La noche de Mantequilla'. En Cuentos Completos I, Madrid, Alfaguara, 211-220.

Cortázar, J. (2004). 'Segundo viaje'. En Cuentos Completos II, Madrid, Alfaguara, 434-442.

Cortázar, J. (2004). 'Torito'. En Cuentos Completos I, Madrid, Alfaguara, 360-365.

Faulkner, W. (2008). ¡Absalón, Absalón!, Barcelona, Belacqua.

Fontanarrosa, R. (2004). 'Regreso al cuadrilátero'. En Cuentos reunidos 1, Bogotá, Alfaguara, 724- 728.

Garibay, R. (1979). Las glorias del gran Púas, México, Grijalbo.

Hemingway, E. (1981). 'El boxeador'. En The Nick Adams stories, NY, Scribner.

Hemingway, E. (2003). 'Cincuenta de a mil'. En Ernest Hemingway, Autores Selectos, México, Grupo Editorial Tomo, 395- 417.
Homero, (1973). 'Canto XXIII'. En La Ilíada, Bogotá, Carvajal.

Irusta, C. (2006). Boxeo: las mejores entrevistas de Carlos Irusta en el Gráfico, Buenos Aires, Kier, Colección el Sendero del Guerrero.

Joyce, C. (1990). Del boxeo, Barcelona, Tusquets Editores.

Lardner, R. (1984). 'El campeón'. En Andrés Bello Cuentos norteamericanos, Madrid,157- 183.

London, J. (2000). Un bistec'. En Ley de vida y otros cuentos, Madrid, Ediciones Clásicos universales, 166- 186.

Mailer, N. (2005). 'El combate del siglo'. En América, Barcelona, Anagrama, 321- 388.

Palou, Á. (2003). Con la muerte en los puños, México, Alfaguara.

Pérez, A. (2008). El síndrome de Mowgli, Sevilla, Algaida.

Rodríguez, F. (2000). El precio de la gloria, Barcelona, Tot Editorial.

Rodríguez, F. (2003). Los grandes campeones de los pesos pesados, Barcelona, El Cobre.

Rosa, J. de la. (2008). Guantes de seda, Sevilla, Algaida.

Soriano, O. (1983). 'José María Gatica: un odio que no conviene olvidar'. En De artistas, locos y criminales, Editorial Bruguera.

Talese, G. (1995). Fama y oscuridad, Nueva York, Random House Publishing Group.

Talese, G. (2008). 'El perdedor'. En Retratos y Encuentros, Bogotá, Aguilar, 79- 105.

Talese, G. (2008). Retratos y Encuentros, Madrid, Aguilar.

Toledo, A. (2005). De puño y letra. Historias de boxeadores, México, Ficticia.

Torres, D. (2008). Niños de tiza, Sevilla, Algaida.

Wacquant, L. (2006). Entre las cuerdas. Cuadernos de un aprendiz de un boxeador, Buenos Aires, Siglo XXI.

Wodehouse. P.G. (1981). Las disparatadas aventuras de Ukridge, Barcelona, Bruguera.

\section{En Colombia}

Galvis, A. (1997). Grandes hazañas deportivas de Colombia, Bogotá, Ediciones Martínez Roca.

Gómez, M. (2006). Asalto 16: confesiones de la Centella Negra, Bogotá, Andina Ediciones.

Hoyos, A. (1994). 'Kaos'. En Los viudos y otros cuentos, Santafé de Bogotá, Tercer Mundo Editores.

Jimeno, R. (1993). El ocaso de los ídolos, Revista Número No 2., 2-5.

Porto, M. (1978). Rocky Valdéz: el cóndor del ring, Bogotá, Plaza \& Janes.

Porto, R. (2002). Historia del boxeo colombiano, Cartagena, Litohermedin.

Porto, R. (2008). El deporte en Cartagena de Indias, Cartagena, Editorial Universitaria.

Salcedo, A. (2005). El Oro y la Oscuridad. La vida gloriosa y trágica de Kid Pambelé, Bogotá, Editorial Debate.

Sánchez-Juliao, D. (1981). Abraham al humor, el Pachanga y el Flecha, Bogotá, Tiempo Americano Editores. 
Púgilteca (películas de boxeo)

Luces de la ciudad (City Lights) (1931). Director y actor: Charles Chaplin.

Más dura será la caída (1956). Director: Mark Robson.

Nido de ratas (On The Waterfront) (1954). Director: Elia Kazan.

Rocky I (1976). Dirección: John G. Avildsen.

Toro Salvaje (1980). Dirección: Martin Scorcese. 